\title{
Multiple myometrial cysts micmicking multiple fibroid uterus
}

\section{B. Ramesh, Rachana Ghanti*, Veena Devadiga}

Department of Gynec Laparoscopy, Altius Hospital, Bangalore, Karnataka, India

Received: 24 March 2017

Accepted: 22 April 2017

\section{*Correspondence:}

Dr. Rachana Ghanti,

E-mail: rachana.ghanti@gmail.com

Copyright: (c) the author(s), publisher and licensee Medip Academy. This is an open-access article distributed under the terms of the Creative Commons Attribution Non-Commercial License, which permits unrestricted non-commercial use, distribution, and reproduction in any medium, provided the original work is properly cited.

\begin{abstract}
Adenomyosis is the presence of endometrial glands and stroma in the context of the myometrium, with adjacent smooth muscle hyperplasia. It may be diffuse or cystic. Adenomyotic cysts of the uterus are extremely rare. A 31 years old nulligravida woman presented to our OPD with complaints of severe dysmenorrhea and back pain since 8 months. Transvaginal ultrasound revealed retroverted uterus with diffuse adenomyosis with intramyometrial endometriotic cysts in both cornual areas, both adnexa showing multiple small endometriotic cysts. On Laparoscopy cystic masses around $5 \times 4 \mathrm{~cm}$ was found near the cornua and anterior uterine wall, which were excised and diagnosed as adenomyotic cyst on histopathology.
\end{abstract}

Keywords: Adenomyosis, Adenomyotic cyst, Dysmenorrhea, Excision

\section{INTRODUCTION}

Adenomyosis usually affects women aged $<30$ years who have never undergone any gynecologic surgical intervention. Diffuse adenomyosis occurs more commonly, with clinical findings of cystic spaces filled with blood, usually $<5 \mathrm{~mm}$ in greatest diameter. Cysts $\geq 1 \mathrm{~cm}$ in diameter are uncommon. Large adenomyotic cysts are lined with ectopic functional endometrium - like tissue and are characterized by cyclic changes with epithelial exfoliation and hemorrhagic infarction of adjacent smooth muscle. Adenomyotic cysts of the uterus are extremely rare. The potential mechanisms of pathophysiology of adenomyosis can be explained by endomyometrial invagination or estrogen stimulation or iatrogenic implantation during uterine surgery.

\section{CASE REPORT}

A 31 years old nulligravida woman presented to our OPD with complaints of severe dysmenorrheal and back pain since 8 months. She was married for 2 years and was trying to conceive. She underwent diagnostic laparoscopy in the past for similar complaints, which revealed? Bicornuate v/s multiple fibroid uterus. On examination, her vital signs were stable and she had right iliac fossa tenderness. Pelvic examination revealed a normal vagina, vulva and adnexae and an enlarged retroverted uterus. Laboratory findings including complete blood count, liver and renal function tests and hormonal profile was normal. Transvaginal ultrasound revealed retroverted uterus with diffuse adenomyosis with intramyometrial endometriotic cysts in both cornual areas, both adnexa showing multiple small endometriotic cysts.

Laparoscopy was performed with patient under general anesthesia. With the patient in a lithotomy position, pneumoperitoneum was induced using a Veress needle, and trocars were inserted. Intra op - cystic masses around $5 \times 4 \mathrm{~cm}$ were noted near both the cornua and anterior uterine wall. Both tubes were normal. Left ovary was buried under adhesions and right ovary was normal. Diluted Inj vasopressin (20U in $200 \mathrm{ml}$ Normal saline) was injected into uterus, till it blenched (Figure 1a, 1b). Uterine wall overlying the cystic masses was incised 
using harmonic energy source and chocolate colored fluid was drained (Figure 1c). The cystic masses were excised circumferentially protecting the surrounding myometrial tissue (Figure 1d). Since there was no defect in the uterine wall, raw areas were left alone without suturing (Figure 1e). Patient was discharged on third postoperative day. Her recovery and follow up period was eventful. Her symptoms of pain dissolved one month after the surgery.
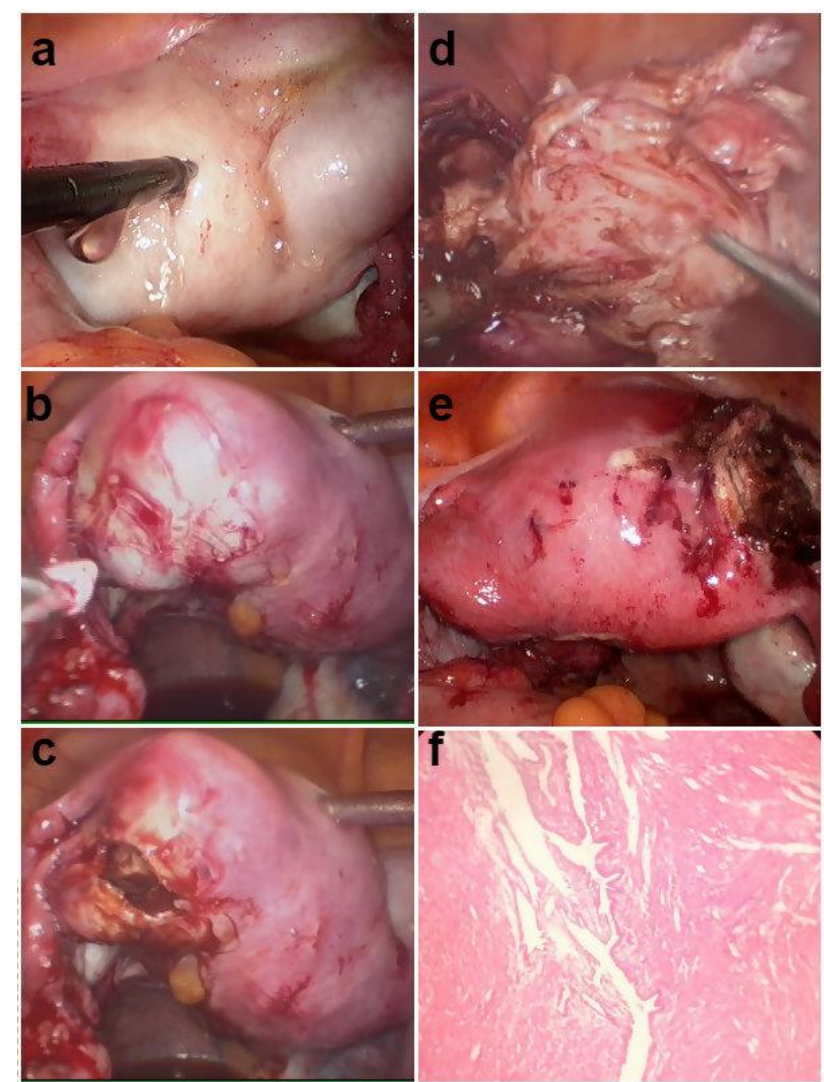

(a. Diluted Inj Vasopressin infiltration; b. Cystic lesion noted near both cornua; c. Cyst cavity after incision and drainage of chocolate colored fluid; d. Excision of cyst with surrounding myometrium; e. Raw surface after excision of the adenomyotic cyst; f. Microscopy showing cystic changes lined by cuboidal epithelium and endometrial glands with stroma)

\section{Figure 1: Laparoscopic and histology images of} multiple adenomyotic cysts.

Histopathology report of the cyst wall revealed adenomyotic cyst. At macroscopic examination, multiple grey brown mass of tissue was seen, largest measuring $4 \times 4 \mathrm{~cm}$. On microscopy- smooth muscle cells seen separated by connective tissue. In the stroma few lymphocytes, cystic degeneration lined by flat cuboidal epithelium at few areas and endometrial stroma with glands lined by tall cuboidal epithelium.

\section{DISCUSSION}

Cystic structures within the uterine cavity are uncommon. ${ }^{1}$ Uterine cysts are classified into 2 main groups: congenital and acquired. Acquired cysts include cystic degeneration of uterine leiomyoma, cystic adenomyosis, and serosal cysts. Congenital cysts derive from mullerian duct anomalies such as noncommunicating rudimentary horn and a unicornuate uterus or can be represented by wollfian duct or mullerian duct cyst. $^{2}$

Several terms have been used to define these large cysts including adenomyotic cyst, cystic adenomyoma, and cystic adenomyosis. According to Takechi et al, adenomyoma is a neoplastic tumor classified as a benign mixed epithelial - nonepithelial tumor. ${ }^{3}$ The designation of adenomyoma should be reserved for polypoid lesions in which the stromal component is almost exclusively composed of smooth muscle.

Small adenomyotic cysts that do not usually exceed $5 \mathrm{~mm}$ in diameter are found in $24 \%$ of hysterectomy specimens] but larger cysts are extremely rare. ${ }^{4}$ Considering patient age at symptom occurrence, the cysts can be classified into adult and juvenile forms. The adult forms seem to result from trauma at the endometrium-myometrium interface, e.g., after uterine instrumentation. ${ }^{5}$ The juvenile form is considered a congenital disease that develops from duplication and persistence of ductal mullerian tissue in a critical area, close to the root of round ligament, possibly related to gubernaculums dysfunction.

Pelvic pain, dysmenorrhea, menorrhagia and large sized uterus are the most common clinical features of adenomyosis. Pain or severe dysmenorrhea can also be main symptoms in adenomyotic cysts. In our case, patient mainly complained of dysmenorrhea and backache.

Magnetic resonance imaging is important in the accurate diagnosis of cystic adenomyosis especially when findings from other imaging modalities are nonspecific. Imaging techniques are critical in differential diagnosis of adenomyotic cysts and help us to choose the appropriate intervention by also taking into account the size and the localization of the cyst and age of the patient.

In young patients, hormonal ablative therapy is the first choice and can be accomplished by oral contraceptives. In the presence of severe symptoms that do not diminish with medical therapy, a surgical intervention can be planned that aims total excision of the adenomyotic cyst. Laparoscopy combined with hysteroscopy is ideal for complete surgical treatment. In older patients with no desire to preserve their fertility and especially in cases when adenomyotic cysts are accompanied by diffuse adenomyosis, hysterectomy should be performed.

Histologically, adenomyotic cysts are cavities lined by endometrial epithelium. The stroma below the epithelium is thin throughout the cyst and contains red blood cells and hemosiderin-laden macrophages. The stromal cells are morphologically similar to those of the endometrium, as in endometriosis. 
Funding: No funding sources

Conflict of interest: None declared

Ethical approval: Not required

\section{REFERENCES}

1. Muzii L, Marana R, Angioli R, Bianchi A, Cucinella $\mathrm{G}$, Vignali $\mathrm{M}$ et al. Histologic analysis of specimens from laparoscopic endometrioma excision performed by different surgeons: does the surgeon matter? Fertil Steril. 2011;95:2116-9.

2. Kim NR, Cho HY, Ha SY. Intramyometrial uterine cysts with special reference to ultra structural findings: report of two cases. J Obstet Gynaecol Res. 2011;37:259-63.

3. Takeuchi H, Kitade M, Kikuchi I, Kumakiri J, Kuroda K, Jinushi M. Diagnosis laparoscopic management and histopathological findings of juvenile cystic adenomyoma: a review of nine cases. Fertil Steril. 2010;94:862-68.

4. English DP, Verma U, Pearson JM. Uterine cyst as a cause of chronic pelvic pain: a case report. J Reprod Med. 2012;57:446-8.

5. Kriplani A, Mahey R, Agarwal N, Bhatla N, Yadav R, Singh MK. Laparoscopic management of juvenile cystic adenomyoma: four cases. J Minim Invasive Gynecol. 2011;18:343-8.

Cite this article as: Ramesh $\mathrm{B}$, Ghanti $\mathrm{R}$, Devadiga V. Multiple myometrial cysts micmicking multiple fibroid uterus. Int J Reprod Contracept Obstet Gynecol 2017;6:2651-3. 